\title{
PERAMALAN HARGA EMAS INDONESIA MENGGUNAKAN METODE FUZZY TIME SERIES KLASIK
}

\author{
FALDO ADITYA, DODI DEVIANTO, MAIYASTRI \\ Program Studi S1 Matematika, \\ Fakultas Matematika dan Ilmu Pengetahuan Alam, Universitas Andalas, \\ Kampus UNAND Limau Manis Padang, Indonesia. \\ email : faldoaditya29@gmail.com
}

Diterima 22 Juni 2019 Direvisi 6 Juli 2019 Dipublikasikan 4 Agustus 2019

\begin{abstract}
Abstrak. Emas merupakan jenis investasi yang diminati para investor karena memiliki tingkat resiko yang relatif rendah, berfungsi sebagai pelindung kekayaan dan tidak terpengaruhi oleh inflasi. Harga emas selalu mengalami perubahan dari waktu ke waktu, sehingga perlu dilakukan peramalan nilai harga emas Indonesia sebagai dasar bagi para investor dalam pengambilan keputusan. Metode peramalan yang dapat digunakan salah satunya adalah metode Fuzzy Time Series Klasik. Hasil peramalan dari metode tersebut kemudian diukur tingkat akurasinya menggunakan Mean Absolute Percentage Error (MAPE). Pada penelitian ini, hasil peramalan harga emas Indonesia mengikuti pola data pergerakan harga emas aktual. Sementara nilai akurasi peramalan MAPE yaitu sebesar 0,99\%, sehingga peramalan harga emas Indonesia dengan metode Fuzzy Time Series klasik berdasarkan kriteria MAPE tergolong sangat baik.
\end{abstract}

Kata Kunci: Emas, Time Series, Fuzzy Time Series

\section{Pendahuluan}

Investasi merupakan bentuk pengelolaan dana guna memberikan keuntungan dengan cara menempatkan dana tersebut pada alokasi yang diperkirakan akan memberikan tambahan keuntungan (compounding) [5]. Pelaku investasi disebut investor. Pasar memungkinkan investor untuk mengalokasikan uang yang dimiliki untuk aset yang lain, seperti emas (emas batangan), batu mulia, real estate, barang antik, dan perangko. Emas merupakan salah satu jenis investasi yang diminati investor karena memiliki beberapa keunggulan dibandingkan dengan aset yang lain.

Harga emas terus mengalami perubahan dari waktu ke waktu. Pergerakan harga emas yang akan datang tersebut dapat dipantau dengan menggunakan peramalan. Dengan melakukan peramalan, maka akan memberikan dasar bagi para investor dalam perencanaan dan pengambilan keputusan untuk meningkatkan keuntungan serta mencegah terjadinya kerugian. Risk dan return merupakan prinsip utama dari investasi. return adalah laba dari investasi sedangkan risk adalah kemungkinan mengalami kerugian dalam investasi. Pada umumnya hubungan antara return dan 
risk adalah linear. Umumnya, risiko yang lebih rendah diambil, keuntungan yang diperoleh lebih rendah dan sebaliknya. Prinsip-prinsip ini penting bagi investor sebelum membuat kesepakatan investasi [3].

Terdapat beberapa metode yang dapat digunakan untuk melakukan peramalan, salah satunya adalah fuzzy time series klasik. Fuzzy Time Series (FTS) merupakan penerapan matematika fuzzy di bidang time series. Fuzzy Time Series pertama kali diusulkan oleh Song dan Chissom yang diterapkan dalam konsep logika fuzzy untuk mengembangkan dasar dari fuzzy time series dengan menggunakan metode time invariant dan time variant yang digunakan untuk memodelkan peramalan jumlah pendaftar di suatu Universitas [1].

Pada tulisan ini akan diterapkan metode FTS Klasik untuk meramalkan harga emas harian Indonesia. Selanjutnya hasil peramalan tersebut akan diukur tingkat akurasinya menggunakan metode Mean Absolute Percentage Error (MAPE).

\section{Model Peramalan Data Time Series dengan Fuzzy Time Series Klasik}

\subsection{Peramalan}

Peramalan sering dilakukan untuk memprediksi dan membuat perencanaan dengan menggunakan data masa lalu dan data masa sekarang, agar dapat membuat prediksi. Peramalan merupakan alat bantu yang sangat penting dalam perencanaan yang efektif dan efisien khususnya dalam bidang ekonomi dan bisnis [7].

Peramalan biasanya diklasifikasikan berdasarkan waktu masa depan yang dicakupnya, yaitu jangka pendek, jangka menengah, dan jangka panjang. Peramalan jangka pendek memprediksi peristiwa dalam periode waktu harian, mingguan, dan bulanan. Peramalan jangka menengah dari satu hingga dua tahun kedepan dan peramalan jangka panjang mencakup lebih dari dua tahun [7].

Metode peramalan yang tepat digunakan untuk meramal jangka pendek dan menengah yaitu dengan menggunakan model Autoregressive Integrated Moving Average (ARIMA) [4]. Selain itu metode Fuzzy Time Series juga tepat untuk meramal jangka pendek dan menengah. Sementara untuk peramalan jangka panjang, metode peramalan yang tepat digunakan yaitu dengan menggunakan model Autoregressive Fractionally Integrated Moving Average (ARFIMA), terutama terhadap pendekatan ekonomi makro konvensional [2]. Kedua model tersebut merupakan metode peramalan time series klasik.

Peramalan menggunakan data time series untuk diidentifikasi pola datanya yang nantinya akan digunakan untuk melakukan peramalan. Sebagai contoh yaitu data curah hujan. Data curah hujan merupakan data deret waktu, dengan mengidentikasi pola dari data masa lalu, akan dilakukan peramalan misalnya untuk memperoleh prediksi suhu udara di masa yang akan datang [6]. Selain itu, terdapat data time series lainnya yang dapat dianalisis dan diolah untuk dilakukan suatu teknik peramalan. 


\subsection{Fuzzy Time Series Klasik}

Fuzzy Time Series (FTS) merupakan pendekatan baru yang dikembangkan dangan menyelesaikan masalah data linguistik. Pendekatan ini menggabungkan variabel linguistik dengan proses analisis penerapan logika fuzzy ke dalam data time series untuk mengatasi ketidakjelasan data.

Konsep dasar FTS pertamakali diperkenalkan oleh Song dan Chissom pada tahun 1993, dimana nilai fuzzy time series direpresentasikan dalam himpunan fuzzy. Misal $U$ adalah semesta pembicaraan dengan $U=\left\{u_{1}, u_{2}, u_{3}, \cdots, u_{n}\right\}$, dimana $u_{i}$ adalah nilai linguistik yang mungkin dari $U$ kemudian sebuah himpunan fuzzy variabel linguistik $A_{i}$ dari $U$ didefinisikan sebagai berikut :

$$
A_{i}=\frac{f_{A_{i}}\left(u_{1}\right)}{u_{1}}+\frac{f_{A_{i}}\left(u_{2}\right)}{u_{2}}+\cdots+\frac{f_{A_{i}}\left(u_{n}\right)}{u_{n}}
$$

dimana $f_{A_{i}}$ adalah fungsi keanggotaan himpunan fuzzy $A_{i}$, sehingga $f_{A_{i}} \rightarrow[0,1]$. $u_{k}$ adalah elemen dari himpunan fuzzy $A_{i}$ dan $f_{A_{i}}\left(u_{k}\right)$ adalah derajat keanggotaan dari $u_{k}$ pada $A_{i}$, dengan $k=1,2,3, \cdots, n$.

Definisi 2.1. [1] Misalkan himpunan semesta $Y(t)(t=\cdots, 0,1,2, \cdots, n, \cdots)$ adalah subset dari $R$ yang didefinisikan dengan himpunan fuzzy $A_{i}$. Jika $F(t)$ terdiri dari $A_{i}(i=1,2, \cdots, n), F(t)$ didefinisikan sebagai FTS pada $Y(t)(t=$ $\cdots, 0,1,2, \cdots, n, \cdots)$.

Definisi 2.2. [1] Jika $F(t)=A_{i}$ dan $F(t-1)=A_{j}$ maka hubungan antara $F(t)$ dan $F(t-1)$ disebut sebagai fuzzy logical relationship (FLR). Hubungan ini dapat dinyatakan dengan $A_{i} \rightarrow A_{j}$, dimana $A_{i}$ disebut left-hand side (LHS) dan $A_{j}$ disebut right-hand side (RHS)dari FLR. Jika terdapat dua FLR mempunyai himpunan fuzzy yang sama ( $L H S A_{i} \rightarrow A_{j 1}, A_{i} \rightarrow A_{j 2}$ ), maka dapat dikelompokkan ke dalam fuzzy logical relationship group $(F L R G) A_{i} \rightarrow A_{j 1}, A_{j 2}$.

Berikut beberapa langkah untuk menyelesaikan model Fuzzy Time Series [1]. Langkah 1. Mengumpulkan data historis dan mendefinisikan himpunan semesta $U$.

Pada tahap ini, ditentukan nilai minimum $\left(D_{\min }\right)$ dan maksimum $\left(D_{\max }\right)$ dari data historis. Berikutnya tentukan nilai $D_{1}$ dan $D_{2}$, dimana nilai tersebut ditentukan secara bebas oleh peneliti selama kedua nilai bilangan tersebut masih real positif. Nilai $D_{1}$ dan $D_{2}$ bertujuan untuk mempermudah dalam pembentukan interval.

Berikut adalah rumus himpunan semesta $U$ :

$$
U=\left[D_{\min }-D_{1}, D_{\max }+D_{2}\right]
$$

dimana $D_{\text {min }}$ adalah nilai minimum, $D_{\max }$ adalah nilai maksimum, serta $D_{1}$ dan $D_{2}$ adalah nilai bilangan positif yang sesuai.

Langkah 2. Menentukan jumlah dan panjang interval.

Pada tahap ini, himpunan semesta $U$ dipartisi (dibagi) menjadi beberapa bagian dengan interval $(n)$ yang sama dengan menggunakan rumus Sturges berikut [8] :

$$
n=1+3.322 \log N,
$$


dengan $N$ adalah banyaknya data historis.

Selanjutnya menentukan panjang interval, dengan menggunakan rumus sebagai berikut :

$$
l=\frac{\left[\left(D_{\max }+D_{2}\right)-\left(D_{\min }-D_{1}\right)\right]}{n},
$$

dimana $l$ adalah panjang interval dan $n$ adalah banyak interval.

Masing-masing interval dapat dihitung dengan,

$$
u_{n}=\left[D_{\min }-D_{1}+(n-1) l ; D_{\min }-D_{1}+n l\right] .
$$

Langkah 3. Menentukan himpunan fuzzy untuk seluruh himpunan semesta $U$.

Tidak terdapat batasan untuk menentukan banyaknya variabel li- nguistik yang dapat menjadi himpunan fuzzy. Untuk mempermudah, setiap himpunan fuzzy $A_{i}(i=1,2, \cdots, n)$ didefinisikan dalam jumlah $n$ interval, yaitu $u_{1}=\left[d_{1}, d_{2}\right], u_{2}=$ $\left[d_{2}, d_{3}\right], u_{3}=\left[d_{3}, d_{4}\right], u_{4}=\left[d_{d}, d_{5}\right], \cdots, u_{n}=\left[d_{n}, d_{n+1}\right]$.

Aturan untuk menentukan derajat keanggotaan $u_{i}$ adalah sebagai berikut :

$$
A_{i}=\sum_{j=1}^{n} \frac{\mu_{i j}}{u_{i j}}
$$

dengan $\mu_{i j}$ adalah derajat keanggotaan $u_{i j}$ milik $A_{i}$ yang ditentukan:

$$
\mu_{i j}= \begin{cases}1, & i=j \\ 0.5, & j=i-1 \text { atau } i=j-1 \\ 0, & \text { lainnya }\end{cases}
$$

Langkah 4 : Melakukan fuzzyfikasi terhadap data historis.

Fuzzyfikasi merupakan proses mengidentifikasi data ke dalam fuzzy set. Jika sebuah data historis yang dikumpulkan termasuk ke dalam interval $u_{i}$, maka data tersebut difuzzyfikasi ke dalam $A_{i}$.

Langkah 5 : Menentukan fuzzy logical relation (FLR) dan fuzzy logical relation group (FLRG).

FLR dan FLRG dapat ditentukan berdasarkan Definisi 2.2.

Langkah 6 : Menghitung output yang akan diramalkan.

Jika $F(t-1)=A_{j}$, peramalan dari $F(t)$ dapat ditentukan dengan aturan-aturan dasar berikut.

(a) Jika FLRG dari $A_{j}$ adalah himpunan kosong $\left(A_{j} \rightarrow \varnothing\right)$, maka peramalan dari $F(t)$ adalah $m_{j}$ yang merupakan titik tengah dari interval $u_{j}$ adalah

$$
F(t)=m_{j}
$$

(b) Jika FLRG dari $A_{j}$ adalah himpunan satu ke satu $\left(A_{j} \rightarrow A_{k}, j, k=1,2, \cdots, n\right)$, maka peramalan dari $F(t)$ adalah $m_{k}$ yang merupakan titik tengah dari interval $u_{k}$ adalah

$$
F(t)=m_{k}
$$


(c) Jika FLRG dari $A_{j}$ adalah himpunan satu ke banyak $\left(A_{j} \rightarrow A_{1}, A_{3}, A_{5}, j=\right.$ $1,2, \cdots, n)$, maka peramalan dari $F(t)$ adalah $m_{1}, m_{3}, m_{5}$ yang merupakan titik tengah dari interval $u_{1}, u_{3}, u_{5}$ adalah

$$
F(t)=\frac{\left(m_{1}+m_{3}+m_{5}\right)}{3}
$$

\subsection{Akurasi Peramalan}

Perhitungan error merupakan suatu cara untuk mengetahui ketepatan model yang telah diperoleh. Dengan perhitungan error dapat dilihat sebe-rapa akurat data hasil peramalan dari model yang telah diperoleh dengan data aktualnya. Salah satu metode peramalan yang dapat digunakan yaitu Mean Absolute Percentage Error(MAPE). MAPE merupakan rata-rata dari keseluruhan persentase kesalahan (selisih) antara data aktual dengan data hasil peramalan [9]. MAPE dapat diperoleh dengan rumus sebagai berikut,

$$
M A P E=\frac{1}{n} \sum_{t=1}^{n} \frac{|X(t)-F(t)|}{X(t)} \times 100 \%
$$

Kriteria keakuratan MAPE adalah sebagai berikut.

(1) Ketepatan peramalan sangat baik saat nilai MAPE $<10 \%$.

(2) Ketepatan peramalan baik saat nilai MAPE $10 \%-20 \%$.

(3) Ketepatan peramalan cukup saat nilai MAPE $20 \%-50 \%$.

(4) Ketepatan peramalan tidak akurat saat nilai MAPE $>50 \%$.

\section{Pembahasan}

Data yang digunakan adalah data harga emas harian Indonesia periode 1 September 2018 hingga 31 Maret 2019 yang diperoleh dari https://harga-emas.org/. Data dinyatakan dalam satuan Rupiah. Selanjutnya dari data time series emas akan diramalkan harga emas yang akan datang, yaitu harga emas pada tanggal 1 April 2019. Tahap awal yang dilakukan yaitu mendefinisikan himpunan semesta $U$ berdasarkan persamaan $(2.2)$, yaitu $U=[563000,60800]$. Kemudian himpunan $U$ dibagi menjadi beberapa interval dengan menggunakan persamaan (2.3), (2.4), dan (2.5), yaitu $u_{1}=[563000,568000], u_{2}=[568000,573000], u_{3}=[573000,578000]$, $u_{4}=[578000,583000], u_{5}=[583000,588000], u_{6}=[588000,593000], u_{7}=$ [593000, 598000], $u_{8}=[598000,603000]$, dan $u_{9}=[603000,608000]$.

Tahap selanjutnya menentukan himpunan fuzzy untuk seluruh himpunan semesta $U$ pada setiap data. Berdasarkan aturan penentuan derajat keanggotaan pada persamaan (2.6) dan (2.7) maka himpunan fuzzy yang terbentuk sebagai 
berikut :

$$
\begin{aligned}
& A_{1}=\frac{1}{u_{1}}+\frac{0,5}{u_{2}}+\frac{0}{u_{3}}+\frac{0}{u_{4}}+\frac{0}{u_{5}}+\frac{0}{u_{6}}+\frac{0}{u_{7}}+\frac{0}{u_{8}}+\frac{0}{u_{9}} \\
& A_{2}=\frac{0,5}{u_{1}}+\frac{1}{u_{2}}+\frac{0,5}{u_{3}}+\frac{0}{u_{4}}+\frac{0}{u_{5}}+\frac{0}{u_{6}}+\frac{0}{u_{7}}+\frac{0}{u_{8}}+\frac{0}{u_{9}} \\
& A_{3}=\frac{0}{u_{1}}+\frac{0.5}{u_{2}}+\frac{1}{u_{3}}+\frac{0,5}{u_{4}}+\frac{0}{u_{5}}+\frac{0}{u_{6}}+\frac{0}{u_{7}}+\frac{0}{u_{8}}+\frac{0}{u_{9}} \\
& A_{4}=\frac{0}{u_{1}}+\frac{0}{u_{2}}+\frac{0,5}{u_{3}}+\frac{1}{u_{4}}+\frac{0,5}{u_{5}}+\frac{0}{u_{6}}+\frac{0}{u_{7}}+\frac{0}{u_{8}}+\frac{0}{u_{9}} \\
& A_{5}=\frac{0}{u_{1}}+\frac{0}{u_{2}}+\frac{0}{u_{3}}+\frac{0,5}{u_{4}}+\frac{1}{u_{5}}+\frac{0,5}{u_{6}}+\frac{0}{u_{7}}+\frac{0}{u_{8}}+\frac{0}{u_{9}} \\
& A_{6}=\frac{0}{u_{1}}+\frac{0}{u_{2}}+\frac{0}{u_{3}}+\frac{0}{u_{4}}+\frac{0,5}{u_{5}}+\frac{1}{u_{6}}+\frac{0,5}{u_{7}}+\frac{0}{u_{8}}+\frac{0}{u_{9}} \\
& A_{7}=\frac{0}{u_{1}}+\frac{0}{u_{2}}+\frac{0}{u_{3}}+\frac{0}{u_{4}}+\frac{0}{u_{5}}+\frac{0,5}{u_{6}}+\frac{1}{u_{7}}+\frac{0,5}{u_{8}}+\frac{0}{u_{9}} \\
& A_{8}=\frac{0}{u_{1}}+\frac{0}{u_{2}}+\frac{0}{u_{3}}+\frac{0}{u_{4}}+\frac{0}{u_{5}}+\frac{0}{u_{6}}+\frac{0,5}{u_{7}}+\frac{1}{u_{8}}+\frac{0,5}{u_{9}} \\
& A_{9}=\frac{0}{u_{1}}+\frac{0}{u_{2}}+\frac{0}{u_{3}}+\frac{0}{u_{4}}+\frac{0}{u_{5}}+\frac{0}{u_{6}}+\frac{0}{u_{7}}+\frac{0,5}{u_{8}}+\frac{1}{u_{9}}
\end{aligned}
$$

Selanjutnya dilakukan proses fuzzyfikasi dan diperoleh hasil pada Tabel 1.

Tabel 1. Data Terfuzzifikasi

\begin{tabular}{|c|c|c|c|c|c|}
\hline t & Data Aktual & Data Fuzzy & t & Data Aktual & Data Fuzzy \\
\hline 1 & 568089 & $A_{2}$ & 107 & 578917 & $A_{4}$ \\
2 & 568089 & $A_{2}$ & 108 & 584159 & $A_{5}$ \\
3 & 570365 & $A_{2}$ & 109 & 582924 & $A_{4}$ \\
$\vdots$ & $\vdots$ & $\vdots$ & $\vdots$ & $\vdots$ & $\vdots$ \\
104 & 580810 & $A_{4}$ & 210 & 593322 & $A_{7}$ \\
105 & 579548 & $A_{4}$ & 211 & 591738 & $A_{6}$ \\
106 & 578917 & $A_{4}$ & 212 & 591738 & $A_{6}$ \\
\hline
\end{tabular}

Setelah dilakukan proses fuzzifikasi maka tahap selanjutnya adalah menentukan fuzzy logic relations (FLR) dan fuzzy logic relations group (FLRG) sesuai Definisi 2.2 .

Langkah selanjutnya yang dilakukan yaitu meramal harga emas dengan menggunakan metode FTS Klasik berdasarkan persamaan (2.8), (2.9), dan (2.10). Hasil peramalan harga emas Indonesia menggunakan metode FTS klasik disajikan pada tabel berikut : $(\mathbf{X}(\mathbf{t})$ adalah data aktual dan $\mathbf{F}(\mathbf{t})$ adalah hasil peramalan).

Selanjutnya hasil peramalan tersebut dihitung tingkat akurasinya dengan menggunakan MAPE. Nilai MAPE yang diperoleh sebesar 0,99\%, sehingga berdasarkan kriteria keakuratan MAPE nilai peramalan harga emas Indonesia dengan metode FTS klasik tergolong sangat baik. Langkah terakhir yaitu meramal harga emas untuk periode selanjutnya, yaitu 1 April 2019. Berdasarkan persamaan (2.8) dengan 
Peramalan Harga Emas Menggunakan Metode Fuzzy Time Series Klasik 51

Tabel 2. Fuzzy Logical Relationship (FLR)

\begin{tabular}{|c|c|c|c|}
\hline Urutan Data & FLR & Urutan Data & FLR \\
\hline $1-2$ & $A_{2} \rightarrow A_{2}$ & $106-107$ & $A_{4} \rightarrow A_{4}$ \\
$2-3$ & $A_{2} \rightarrow A_{2}$ & $107-108$ & $A_{4} \rightarrow A_{5}$ \\
$3-4$ & $A_{2} \rightarrow A_{2}$ & $108-109$ & $A_{5} \rightarrow A_{4}$ \\
$\vdots$ & $\vdots$ & $\vdots$ & $\vdots$ \\
$103-104$ & $A_{5} \rightarrow A_{4}$ & $209-210$ & $A_{6} \rightarrow A_{7}$ \\
$104-105$ & $A_{4} \rightarrow A_{4}$ & $210-211$ & $A_{7} \rightarrow A_{6}$ \\
$105-106$ & $A_{4} \rightarrow A_{4}$ & $211-212$ & $A_{6} \rightarrow A_{6}$ \\
\hline
\end{tabular}

Tabel 3. Fuzzy Logical Relationship Group (FLRG)

\begin{tabular}{|ccc|}
\hline Current State & & Next State \\
\hline$A_{1}$ & $\rightarrow$ & $4\left(A_{1}\right), 2\left(A_{2}\right)$ \\
$A_{2}$ & $\rightarrow$ & $2\left(A_{1}\right), 23\left(A_{2}\right), 6\left(A_{3}\right), 2\left(A_{4}\right)$ \\
$A_{3}$ & $\rightarrow$ & $7\left(A_{2}\right), 13\left(A_{3}\right)$ \\
$A_{4}$ & $\rightarrow$ & $A_{3}, 9\left(A_{4}\right), 7\left(A_{5}\right), A_{6}, A_{8}$ \\
$A_{5}$ & $\rightarrow$ & $7\left(A_{4}\right), 22\left(A_{5}\right), 2\left(A_{6}\right), A_{7}$ \\
$A_{6}$ & $\rightarrow$ & $3\left(A_{5}\right), 13\left(A_{6}\right), 7\left(A_{7}\right), A_{8}$ \\
$A_{7}$ & $\rightarrow$ & $A_{4}, 8\left(A_{6}\right), 20\left(A_{7}\right), 9\left(A_{8}\right), A_{9}$ \\
$A_{8}$ & $\rightarrow$ & $A_{6}, 11\left(A_{7}\right), 19\left(A_{8}\right), 2\left(A_{9}\right)$ \\
$A_{9}$ & $\rightarrow$ & $3\left(A_{8}\right), 2\left(A_{9}\right)$ \\
\hline
\end{tabular}

Tabel 4. Hasil Peramalan FTS Klasik

\begin{tabular}{|c|l|c|c||c|c|c|c|}
\hline $\mathbf{t}$ & Waktu & $\mathbf{X}(\mathbf{t})$ & $\mathbf{F}(\mathbf{t})$ & $\mathbf{t}$ & Waktu & $\mathbf{X}(\mathbf{t})$ & $\mathbf{F}(\mathbf{t})$ \\
\hline 1 & 1 September 2018 & 568089 & 0 & 107 & 16 Desember 2018 & 578917 & 586500 \\
2 & 2 September 2018 & 568089 & 573000 & 108 & 17 Desember 2018 & 584159 & 586500 \\
3 & 3 September 2018 & 570365 & 573000 & 109 & 18 Desember 2018 & 582924 & 588000 \\
$\vdots$ & $\vdots$ & $\vdots$ & $\vdots$ & $\vdots$ & $\vdots$ & $\vdots$ & $\vdots$ \\
104 & 13 Desember 2018 & 580810 & 588000 & 210 & 29 Maret 2019 & 593322 & 593000 \\
105 & 14 Desember 2018 & 579548 & 586500 & 211 & 30 Maret 2019 & 591738 & 594500 \\
106 & 15 Desember 2018 & 578917 & 586500 & 212 & 31 Maret 2019 & 591738 & 593000 \\
\hline
\end{tabular}

current state yaitu $A_{6}$, maka hasil peramalan harga emas tersebut adalah

$$
F(213)=m_{6}=\frac{588000+593000}{2}=590500 .
$$

Jadi, harga peramalan emas Indonesia pada 1 April 2019 yaitu sebesar 590500, yang artinya harga emas Indonesia diprediksi mengalami penurunan dibandingkan harga emas pada 31 Maret 2019. 


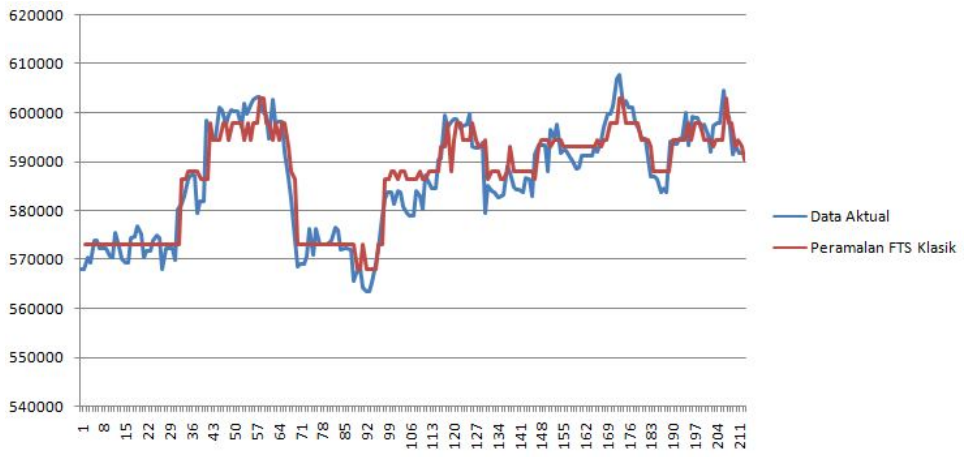

Gambar 1. Peramalan Harga Emas dengan FTS Klasik

\section{Kesimpulan}

Berdasarkan teknik ananlisis data yang telah dilakukan, diprediksi harga emas Indonesia untuk periode selanjutnya mengalami penurunan. Metode Fuzzy Time Series klasik dapat diterapkan untuk berbagai jenis pola data time series, karena metode ini lebih fleksibel dan tidak menyaratkan asumsi asumsi klasik. Berdasarkan hasil peramalan diperoleh tingkat akurasi peramalan dengan menggunakan MAPE sebesar 0,99\%, sehingga hasil peramalan harga emas Indonesia dengan menggunakan metode Fuzzy Time Series Klasik tergolong sangat baik.

\section{Daftar Pustaka}

[1] Cheng, C. S. dkk. 2008. Fuzzy time-series based on adaptive expectation model for TAIEX forecasting. Expert Systems with Applications. 34 : 1126 - 1132

[2] Devianto, D. Maiyastri, and S. Damayanti. 2015. Forecasting long memory time series for stock prices with autoregressive fractionally integrated moving average. Applied Mathematical Sciences. 53(5) : $86-87$

[3] Devianto, D. Maiyastri, and D.R. Fadhilla. 2015. Time series modeling for risk of stock price with value at risk computation. Applied Mathematical Sciences. 9(56) : $2779-2780$

[4] Ekananda, M. 2014. Analisis Data Time Series. Mitra Wacana Media, Jakarta

[5] Indrawati, N and P. Nurmayanti. 2010. Dasar-Dasar Analisis Investasi dan Portofolio. Citrabooks Indonesia, Palembang

[6] Iswahyuli, H. Yozza, D. Devianto. Peramalan curah hujan bulanan desa sungai ipuh solok selatan dengan model autoregressive integrated moving average. Jurnal Matematika UNAND. VII(1) : $85-86$

[7] Montgomery D.C, C.L. Jennings, and M. Kulahci. 2008. Introduction to Time Series Analysis and Forecasting. Jhon Wiley \& Sons, Inc, New Jersey

[8] Sturges, H.A. 1926. The choice of a class interval. Journal of the American Statistical Association. 21 : $65-66$

[9] Tsaur, R.C. 2012. A fuzzy time series-markov chain model with an application to forecast the exchange rate beetween the Taiwan and US Dollar. International Journal of Innovative Computing, Information, and Control. 8(7B) : 4931 4942 